\title{
Calcium-Sensing Receptor Stimulation in Cultured Glomerular Podocytes Induces TRPC6-Dependent Calcium Entry and RhoA Activation
}

\author{
Lei Zhang ${ }^{a}$ Tianrong Jib Qin Wang ${ }^{b}$ Kexin Meng ${ }^{b}$ Rui Zhang ${ }^{b}$ He Yang ${ }^{b}$ \\ Chang Liaob Linlin Ma $^{\mathrm{b}}$ Jundong Jiao ${ }^{\mathrm{b}, \mathrm{c}}$ \\ aDepartment of Pediatrics, The Second Affiliated Hospital, Harbin Medical University, Harbin, \\ ${ }^{b}$ Department of Nephrology, The Second Affiliated Hospital, Harbin Medical University, Harbin, \\ Institute of Nephrology, Harbin Medical University, Harbin, China
}

\section{Key Words}

Trpc6 $\bullet$ Calcium-sensing receptor $\bullet$ RhoA $\bullet$ Podocytes

\begin{abstract}
Background/Aims: Recent studies provided compelling evidence that stimulation of the calcium sensing receptor (CaSR) exerts direct renoprotective action at the glomerular podocyte level. This protective action may be attributed to the RhoA-dependent stabilization of the actin cytoskeleton. However, the underlying mechanisms remain unclear. Methods: In the present study, an immortalized human podocyte cell line was used. Fluo-3 fluorescence was utilized to determine intracellular $\mathrm{Ca}^{2+}$ concentration $\left(\left[\mathrm{Ca}^{2+}\right]_{\mathrm{i}}\right)$, and western blotting was used to measure canonical transient receptor potential 6 (TRPC6) protein expression and RhoA activity. Stress fibers were detected by FITC-phalloidin. Results: Activating CaSR with a high extracellular $\mathrm{Ca}^{2+}$ concentration $\left(\left[\mathrm{Ca}^{2+}\right]_{0}\right.$ ) or R-568 (a type II CaSR agonist) induces an increase in the $\left[\mathrm{Ca}^{2+}\right]$ i in a dose-dependent manner. This increase in $\left[\mathrm{Ca}^{2+}\right]_{i}$ is phospholipase $\mathrm{C}$ (PLC)-dependent and is smaller in the absence of extracellular $\mathrm{Ca}^{2+}$ than in the presence of $0.5 \mathrm{mM}\left[\mathrm{Ca}^{2+}\right]_{0}$. The CaSR activation-induced $\left[\mathrm{Ca}^{2+}\right]_{i}$ increase is attenuated by the pharmacological blockage of TRPC6 channels or siRNA targeting TRPC6. These data suggest that TRPC6 is involved in CaSR activation-induced $\mathrm{Ca}^{2+}$ influx. Consistent with a previous study, CaSR stimulation results in an increase in RhoA activity. However, the knockdown of TRPC6 significantly abolished the RhoA activity increase induced by CaSR stimulation, suggesting that TRPC6-dependent $\mathrm{Ca}^{2+}$ entry is required for RhoA activation. The activated RhoA is involved in the formation of stress fibers and focal adhesions in response to CaSR stimulation because siRNA targeting RhoA attenuated the increase in the stress fiber mediated by CaSR stimulation. Moreover, this effect of CaSR activation on the formation of stress fibers is also abolished by the knockdown of TRPC6. Conclusion: TRPC6 is involved in the regulation of stress fiber formation and focal adhesions via the RhoA pathway in response to CaSR activation. This may explain the direct protective action of CaSR agonists.




\section{Cellular Physiology Cell Physiol Biochem 2017;43:1777-1789

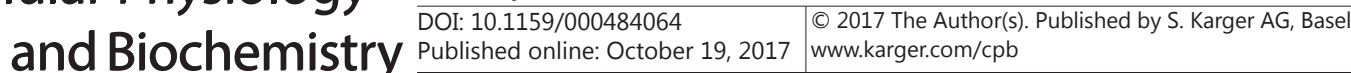 \\ Zhang et al.: Calcium Sensing Receptor Induces TRPC6 Calcium Entry}

\section{Introduction}

The calcium-sensing receptor (CaSR) was originally cloned from parathyroid glands, where it tightly regulates parathyroid hormone secretion in response to changes in extracellular $\mathrm{Ca}^{2+}$ concentration $\left(\left[\mathrm{Ca}^{2+}\right]_{0}\right)[1,2]$. Pharmacological activation of CaSR can be achieved by phenylalkylamine compounds, such as R-568 and cinacalcet. Cinacalcet is currently prescribed for the treatment of secondary hyperparathyroidism in patients with end-stage renal disease. Surprisingly, animal experiments showed that these agents have renoprotective effects beyond the control of calcium homeostasis [3]. In the kidney, CaSR is well-known for regulating calcium secretion and absorption in renal tubules [4]. However, accumulating evidence indicates that CaSR is expressed in glomeruli as well, including mesangial cells and podocytes [5]. Observations from our group and others show that CaSR is expressed in mesangial cells and regulates cell proliferation [6, 7]. Recently, two studies provided compelling evidence that pharmacological activation of CaSR by the calcimimetic R-568 exerts a direct renoprotective effect at the glomerular podocyte level $[8,9]$. This finding may provide a novel treatment option for delaying progressive renal failure. However, very little is currently known about the signaling cascades initiated by CaSR activation in podocytes.

CaSR is a member of the group C G protein-coupled receptor (GPCR) superfamily. Elevations in $\left[\mathrm{Ca}^{2+}\right]_{0}$ or exposure to other CaSR agonists commonly elicit an intracellular calcium signal through interactions between the CaSR and phospholipase C (PLC) [1, 10]. These interactions result in the hydrolysis of phosphatidylinositol-4, 5-bisphosphate by PLC to form inositol-1, 4,5-trisphosphate ( $\mathrm{IP}_{3}$ ) and diacylglycerol (DAG), which lead to an increase in the intracellular $\mathrm{Ca}^{2+}$ concentration $\left(\left[\mathrm{Ca}^{2+}\right]_{\mathrm{i}}\right)$ through the release of $\mathrm{IP}_{3}$-sensitive calcium stores, through the $\mathrm{Ca}^{2+}$ influx or both $[1,10]$. Relatively little is known about the $\mathrm{Ca}^{2+}$ influx mechanism upon CaSR activation. Canonical transient receptor potential (TRPC) channels, nonselective cation channels, seem to be responsible for $\mathrm{Ca}^{2+}$ entry induced by CaSR activation in some cell types, such as salivary ductal cells [11], vascular smooth muscle cells [12,13], keratinocytes [14], MCF-7 breast cancer cells [15] and glomerular mesangial cells [6].

TRPC1, TRPC3, TRPC5 and TRPC6 are expressed in podocytes $[16,17]$. TRPC6, a predominant member of these TRPC channels, plays a vital role in the regulation of cell functions, especially in dynamic actin cytoskeleton regulation $[18,19,20]$. Upon stimulation with angiotensin II or high glucose in podocytes, a TRPC6-mediated $\mathrm{Ca}^{2+}$ influx increases the activity of RhoA, a small Rho GTPase, thereby leading to stress fiber formation to induce a stationary homeostatic podocyte phenotype $[16,21]$. Interestingly, the renoprotective effects of CaSR agonists from cytoskeleton damage is associated with RhoA activity because treatment with the Rho-kinase inhibitor H1152, but not ERK1/2, p38 and JNK inhibitors, abolished R-568-induced increases in stress fiber and focal adhesion formation [9]. Therefore, in the present study, we address whether a TRPC6-dependent $\mathrm{Ca}^{2+}$ influx can be induced by the activation of CaSR and if so, whether it can mediate RhoA activation and be involved in actin cytoskeleton changes induced by CaSR activation.

\section{Materials and Methods}

\section{Cell Culture and Transfection}

An immortalized human podocyte cell line was provided by Dr. Moin Saleem of the Children's Renal Unit and Academic Renal Unit, University of Bristol, Southmead Hospital, Bristol, UK. The cells were cultured as described previously [22]. Briefly, cells were grown at $33^{\circ} \mathrm{C}$ in an RPMI-1640 medium (HyClone, Logan, UT, USA; SH30809.01B) supplemented with ITS (Sigma-Aldrich Co., St. Louis, MO, USA; 13146-5 ML) and $10 \%$ fetal bovine serum (FBS; ScienCell, San Diego, CA, USA; 0500). Human podocytes between passages 4 and 15 were used. To induce differentiation, the cells were cultured at $37^{\circ} \mathrm{C}$ in the same medium in a $5 \% \mathrm{CO}_{2}$ humidified atmosphere for 10-14 days, and the culture medium was changed every 4 days. The human breast 


\section{Cellular Physiology Cell Physiol Biochem 2017;43:1777-1789 \begin{tabular}{l|l|l} 
DOI: 10.1159/000484064 & $\begin{array}{l}\text { O 2017 The Author(s). Published by S. Karger AG, Basel } \\
\text { www.karger.com/cpb }\end{array}$
\end{tabular}}

cancer cell line MCF-7 was obtained from the Cell Bank of the Chinese Academy of Science (Shanghai, China) and maintained in $5 \% \mathrm{CO}_{2}$ at $37^{\circ} \mathrm{C}$ in Dulbecco's modified Eagle's medium (DMEM, HyClone; SH30022.01B) containing 10\% FBS. The cells were transiently transfected with TRPC6 siRNA (Santa Cruz Biotechnology, Inc., Dallas, TX, USA; sc-42672, $10 \mu \mathrm{M}$ ), RhoA siRNA (Santa Cruz Biotechnology, Inc.; sc-29471, $10 \mu \mathrm{M}$ ) or scrambled siRNA (Santa Cruz Biotechnology, Inc., Dallas, TX, USA; sc-37007, $10 \mu \mathrm{M}$ ) using the X-treme GENE siRNA Transfection Reagent (Roche, Basel, Switzerland; 04476093001) according to the manufacturer's instructions. Assays on the transfected cells were conducted within 24-48 h post-transfection.

\section{Reverse-transcription PCR}

Reverse transcription was performed using an RT system (Eppendorf Mastercycler, Hamburg, Germany) in a $10 \mu \mathrm{l}$ reaction mixture. A High Capacity cDNA RT Kit (ABI Applied Biosystems, Foster City, CA, USA) was used for cDNA synthesis according to the manufacturer's instructions. The primer sequences used to amplify CaSR were as follows ( $\left.5^{\prime}-3^{\prime}\right)$ : sense CGGGGTACCTTAAGCACCTACGGCATCTAA and antisense GCTCTAGAGTTAACGCGATCCCAAAGGGCTC. All primers were synthesized by Shanghai Invitrogen Corporation. The PCR cycling conditions for CaSR included one cycle of $10 \mathrm{~min}$ at $95^{\circ} \mathrm{C} ; 40$ cycles of $30 \mathrm{~s}$ at $95^{\circ} \mathrm{C}, 30 \mathrm{~s}$ at $60^{\circ} \mathrm{C}$, and $60 \mathrm{~s}$ at $72^{\circ} \mathrm{C}$; and one cycle of $10 \mathrm{~min}$ at $72^{\circ} \mathrm{C}$. The PCR products were separated on a $1 \%$ agarose gel and stained with ethidium bromide. Reverse transcriptase was omitted as a negative control for the reaction to eliminate amplification from contaminating genomic DNA.

\section{Western blotting}

Western blotting was performed using a standard protocol. Human podocytes were starved for $24 \mathrm{~h}$ in serum-free medium before being stimulated with R-568 (a selective II type CaSR agonist, Tocris Bioscience, Minneapolis, MN, USA; 177172-49-5, DMSO to $100 \mathrm{mM}$ ). In calcium-free medium, the calcium ion chelator ethylenedinitrilotetraacetic acid (EGTA, Sigma-Aldrich Co.; E0396-10 g) was added to obtain a final concentration of $1.0 \mathrm{mM}$. Anti-CaSR (1:200, Santa Cruz Biotechnology, Inc.; sc-33821 $200 \mu \mathrm{g}$, IgG in $1.0 \mathrm{~mL}$ of PBS), anti-TRPC6 (1:200, Alomone Labs, Israel; ACC-017 $200 \mu \mathrm{L}$ ), anti-RhoA (1:500, Santa Cruz Biotechnology, Inc.; sc-418), and anti-actin antibodies (1:1000, ZSGB-Bio, Beijing, China; ZS-TA-09) were used as primary antibodies. Fluorescence-conjugated goat anti-rabbit (1:10000, LI-COR Biosciences, Lincoln, NE, USA; 926-32211) or goat anti-mouse (1:10, 000, LI-COR Biosciences; 926-32210) IgG antibodies were used as secondary antibodies. Band intensities were quantified using the Odyssey infrared imaging system (LI-COR Biosciences).

\section{Immunofluorescence}

Immunofluorescence staining was conducted on cultured podocytes grown on coverslips using a standard protocol. Briefly, after washing, cells were fixed with 4\% paraformaldehyde for $15 \mathrm{~min}$ and permeabilized with $0.4 \%$ Triton X-100 in PBS for $60 \mathrm{~min}$ at room temperature. Nonspecific binding sites were blocked with $50 \%$ goat serum in PBS for $30 \mathrm{~min}$ at $37^{\circ} \mathrm{C}$. After washing with blocking buffer (PBS), the cells were incubated with the appropriate antibody dilutions. For CaSR staining, the cells were incubated with anti-CaSR antibody (1:50) overnight at $4^{\circ} \mathrm{C}$. After washing, the cells were stained with Alexa Fluor 594-conjugated goat anti-mouse secondary antibody (1:500; Molecular Probes, Eugene, OR, USA) for 60 min at room temperature. The nuclei were counterstained with DAPI (1:50; BiYunTian, Beijing, China; C1005-10 ml) for $15 \mathrm{~min}$ at room temperature. After washing, the samples were examined under a laser scanning confocal microscope (Olympus, Tokyo, Japan). Calibrations were performed immediately following each experiment. More than 40 cells were inspected per experiment, and photographs of cells with typical morphology and staining are presented. At least three independent experiments were conducted.

For cytoskeleton staining, human podocytes were starved for $24 \mathrm{~h}$ in a serum-free medium prior to the experiment. Cells were treated for $30 \mathrm{~min}$ with R-568 $(10 \mathrm{nmol} / \mathrm{mL})$. In addition, cells were transfected with TRPC6 siRNA or RhoA siRNA in combination with R-568. The cells were subsequently fixated and stained with vinculin antibodies (1:500, Sigma-Aldrich Co.; v9131-100 $\mu \mathrm{L})$ and the secondary antibody (1:600, Thermo Fisher Scientific Inc. Waltham, MA, USA; Alexa Fluor 594; Z25007). After that, the cells were stained with FITC-phalloidin (1:200 Sigma-Aldrich Co.; p5282-1mg) and then washed 5 times with PBS. The cytoskeleton fluorescence was visualized using a fluorescence microscope (Olympus, Tokyo, Japan). More than 50 cells were inspected per experiment, and three independent experiments were conducted. Quantification analysis of the number of stress fibers was performed, as described previously [16]. Stress 


\section{Cellular Physiology Cell Physiol Biochem 2017;43:1777-1789 \begin{tabular}{ll|l} 
DOI: 10.1159/000484064 & O 2017 The Author(s). Published by S. Karger AG, Basel \\
www.karger.com/cpb
\end{tabular}

fibers were counted manually in each individual cell in independent images. A stress fiber was defined as a phalloidin-positive structure that transverses the entire cell.

Fluorescence measurement of intracellular $\mathrm{Ca}^{2+}\left(\left[\mathrm{Ca}^{2+}\right]_{j}\right)$

Human podocytes were grown on coverslips and loaded in $1 \%$ physiological saline solution containing Pluronic F-127 (0.03\%, Sigma-Aldrich Co.; p2443-1kg) and Fluo-3/AM (3 $\mu$ M, Invitrogen Co., Carlsbad, CA, USA; F1242) at $37^{\circ} \mathrm{C}$ for $45 \mathrm{~min}$. After washing, the coverslips with cells were placed in a chamber containing HEPES-buffered $\mathrm{Na}^{+}$medium (HBM) containing the following (in $\mathrm{mM}$ ): $137 \mathrm{NaCl}, 5 \mathrm{KCl}, 0.5 \mathrm{CaCl}_{2}$, $1.2 \mathrm{MgCl}_{2}, 0.44 \mathrm{KH}_{2} \mathrm{PO}_{4}, 4.2 \mathrm{NaHCO}_{3}, 10$ glucose, and 20 HEPES; the pH was adjusted to 7.4 with $\mathrm{NaOH}$. For $\mathrm{Ca}^{2+}$-free HBM, $\mathrm{Ca}^{2+}$ was omitted. Then, the podocytes were stimulated with a variety of agonists, antagonists or inhibitors as described in the results, including R-568 (a selective II type CaSR agonist, Tocris Bioscience, Minneapolis, MN, USA; 177172-49-5, DMSO to $100 \mathrm{mM}$ ), NPS2390 (an antagonist of CaSR, Sigma-Aldrich Co.; N4786), U73122 (a PLC inhibitor, Sigma-Aldrich Co.; U6756-5MG), U73343 (an inactive analog of U73122, Sigma-Aldrich Co.; U6881-5MG), 2-aminoethoxydiphenyl borate (2-APB, a nonselective TRPC6 blocker, Sigma-Aldrich Co.; D9754-1G), and SKF-96365 (a nonselective TRPC6 blocker, Sigma-Aldrich Co.; S7809-5MG). The fluorescence intensity of Fluo-3 in the cells was recorded with a laser confocal scanning microscope (FV300; Olympus, Japan) [ $\left.\mathrm{Ca}^{2+}\right]$. was expressed as a pseudo-ratio value of the actual fluorescence intensity divided by the average baseline fluorescence intensity. Calibrations were performed immediately following each experiment. Data from 20 to 30 cells were summarized in a single run, and at least three independent experiments were conducted.

\section{RhoA activation assay}

RhoA activity was measured using a Rho activation assay kit (Cytoskeleton, Inc., Denver, CO, USA; BK036-S) according to the manufacturer's instructions. Human podocytes were starved for $24 \mathrm{~h}$ in serumfree medium before being stimulated with R-568. The cells were lysed in cell lysis buffer, and the lysates were immediately clarified by centrifugation at $10,000 \mathrm{xg}, 4^{\circ} \mathrm{C}$ for $1 \mathrm{~min}$. The supernatants were incubated with Rhotekin-Rho binding domain (RBD) glutathione affinity beads, which specifically bind to GTP-bound RhoA. The beads were washed, and the immunoprecipitated complex was resuspended in a $2 \times$ Laemmli sample buffer and subjected to 12\% SDS-PAGE, followed by western blot analysis. The total RhoA protein was determined and used to normalize GTP-bound RhoA densitometric units. At least three independent experiments were conducted.

\section{Statistical analysis}

Data are presented as the mean \pm standard error (SEM). The significance of differences between groups was assessed using two-tailed Student's $t$-test or one-way ANOVA followed by Dunnett's test. A $p$-value < 0.05 was considered to be statistically significant.

\section{Results}

CaSR is present in the cultured human podocytes

First, we examined whether CaSR is expressed in our cultured human podocytes. As shown in Fig. 1A, a 424-bp PCR product was detected after RT-PCR using CaSR-specific primers. In the group without reverse transcriptase (RT-), this amplification product was not detected, indicating that there was no genomic DNA contamination in the RNA samples. A PCR product with the same size as the product from human podocytes was detected in the human breast cancer cell line MCF-7, which was used as a positive control. As shown in Fig. 1B, western blot analysis using a CaSR-specific antibody detected a 160-kDa protein band, representing the mature glycosylated form of CaSR, in both human podocytes and the control MCF-7 cell line. As shown in Fig. 1C, immunofluorescence revealed that CaSR was primarily localized to the cell membrane and cytosol of podocytes. These results determined that the cultured human podocytes express CaSR mRNA and protein. 


\section{Cellular Physiology Cell Physiol Biochem 2017;43:1777-1789

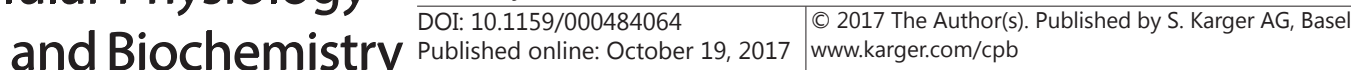

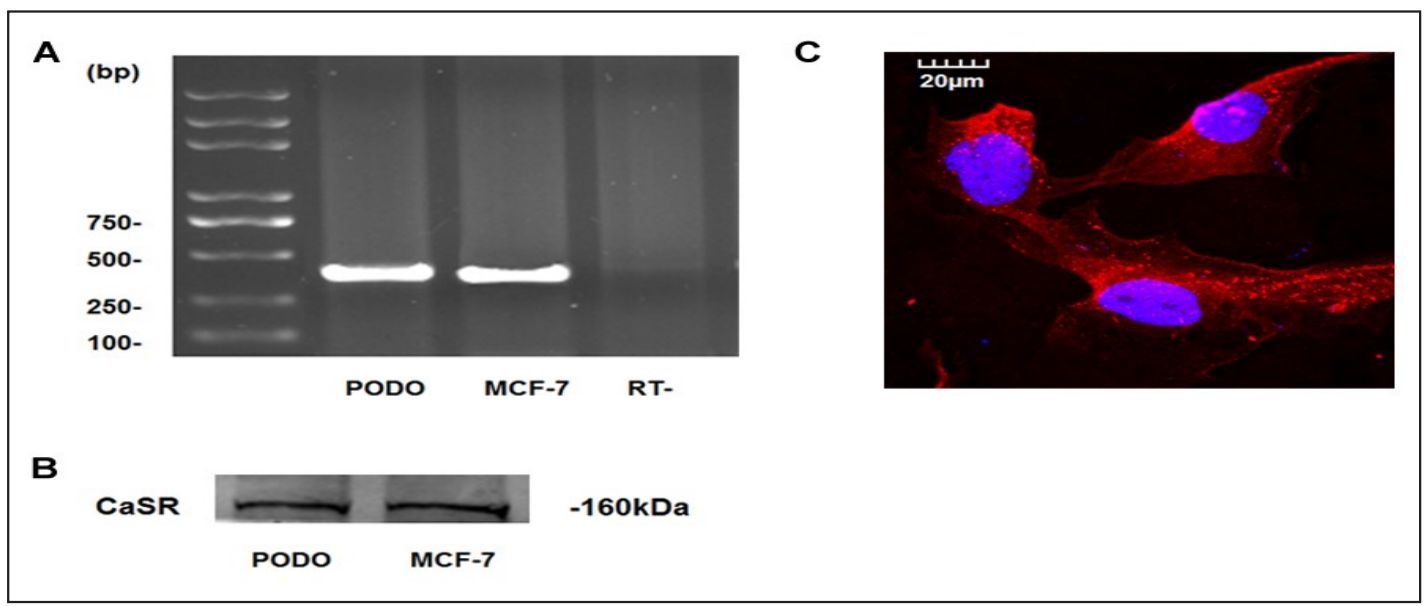

Fig. 1. In vitro cultured human podocytes express CaSR mRNA and protein. (A) RT-PCR was performed on total RNA extracted from podocytes and MCF-7 cells, a human breast cancer cell line, were used as a positive control. Specific primers were used to assess CaSR mRNA expression. A PCR product with an expected size of $424 \mathrm{bp}$ was detected. In the sample without reverse transcriptase (RT-), no PCR products were detected, PODO: podocytes. (B) Western blotting was used to detect CaSR protein expression in human podocytes. A $160-\mathrm{kD}$ band was detected in the podocytes and MCF-7 cells. (C) Immunofluorescence using an anti-CaSR antibody detected CaSR expression in podocytes. Red fluorescence indicates labeled CaSR, and blue fluorescence indicates nuclei. Scale bar: $20 \mathrm{~mm}$. At least 40 cells were observed. A representative image is shown.

\section{Activation of CaSR stimulates an increase $\left[\mathrm{Ca}^{2+}\right]_{i}$ in human podocytes}

To evaluate whether the expression of CaSR protein is associated with the presence of functional receptors, Fluo-3/AM-loaded human podocytes were stimulated by $\mathrm{Ca}^{2+}$ (a type I CaSR agonist) and the calcimimetic compound R-568 (a type II CaSR agonist). As shown in Fig. $2 \mathrm{~A}$, the $\left[\mathrm{Ca}^{2+}\right]_{0}$ change from $1 \mathrm{mmol} / \mathrm{L}$ to $3 \mathrm{mmol} / \mathrm{L}$ triggered a rapid increase in $\left[\mathrm{Ca}^{2+}\right]_{\mathrm{i}}$ to a peak level, which was maintained for more than 300 seconds. The elevated $\left[\mathrm{Ca}^{2+}\right]_{0}$ elicited increases in $\left[\mathrm{Ca}^{2+}\right]_{\mathrm{i}}$ in a dose-dependent manner (Fig. 2B). Stimulation of podocytes by 10 $\mathrm{nmol} / \mathrm{L}$ R-568 produced a response similar to that of $3 \mathrm{mmol} / \mathrm{L}\left[\mathrm{Ca}^{2+}\right]_{0}$ stimulation (Fig. $2 \mathrm{C}$ ). In addition, the $\left[\mathrm{Ca}^{2+}\right]_{\mathrm{i}}$ increase induced by $10 \mathrm{nmol} / \mathrm{L} \mathrm{R}-568$ was dose dependent (Fig. 2D). Furthermore, the $\left[\mathrm{Ca}^{2+}\right]_{\mathrm{i}}$ increase induced by either $3 \mathrm{mmol} / \mathrm{L}\left[\mathrm{Ca}^{2+}\right]_{\mathrm{o}}$ or $10 \mathrm{nmol} / \mathrm{L} \mathrm{R}-568$ was inhibited by pre-incubation with the $10 \mu \mathrm{mol} / \mathrm{L}$ CaSR antagonist NPS2390 for $30 \mathrm{~min}$ (Fig. $2 \mathrm{E}$ and $2 \mathrm{~F}$ ), demonstrating that CaSR activation is not agonist specific. To evaluate whether the increase in $\left[\mathrm{Ca}^{2+}\right]_{\mathrm{i}}$ induced by CaSR activation involves a PLC-dependent pathway, cells were stimulated with CaSR agonists in the presence of the PLC inhibitor U73122 or U73343, an inactive analog of U73122. The $\left[\mathrm{Ca}^{2+}\right]_{\mathrm{i}}$ increase induced by $3 \mathrm{mM}\left[\mathrm{Ca}^{2+}\right]_{\mathrm{o}}$ or $10 \mathrm{nmol} / \mathrm{L}$ R-568 was significantly inhibited by pretreatment with $30 \mu \mathrm{M} \mathrm{U73122}$, as shown in Fig. $2 \mathrm{G}$ and $2 \mathrm{H}$, respectively. However, $30 \mu \mathrm{M}$ U73343 did not inhibit the increase of $\left[\mathrm{Ca}^{2+}\right]_{\mathrm{i}}$ induced by $3 \mathrm{mM}\left[\mathrm{Ca}^{2+}\right]_{0}$ or $10 \mathrm{nmol} / \mathrm{L} \mathrm{R}-568$, as shown in Fig. $2 \mathrm{G}$ and $2 \mathrm{H}$. Taken together, these data confirmed that CaSR protein is functionally expressed in human podocytes and activates a PLC-dependent $\left[\mathrm{Ca}^{2+}\right]_{\mathrm{i}}$ increase.

\section{Activation of CaSR induces TRPC6-dependent $\mathrm{Ca}^{2+}$ influx}

Next, we investigated whether CaSR activation induces $\mathrm{Ca}^{2+}$ influx in human podocytes. Podocytes were stimulated with R-568 in the absence of extracellular $\mathrm{Ca}^{2+}$. As shown in Fig. $3 \mathrm{~A}, 10 \mathrm{nmol} / \mathrm{L} \mathrm{R}-568$ induced a transient $\left[\mathrm{Ca}^{2+}\right]_{\mathrm{i}}$ increase in podocytes. However, the R-568induced $\left[\mathrm{Ca}^{2+}\right]_{i}$ increase in the absence of extracellular $\mathrm{Ca}^{2+}$ was smaller than that observed in the presence of $0.5 \mathrm{mM}\left[\mathrm{Ca}^{2+}\right]_{0}$ and had no subsequent sustained increase in $\left[\mathrm{Ca}^{2+}\right]_{\mathrm{i}}(\mathrm{Fig}$. $3 \mathrm{~B}$ ), suggesting that an extracellular $\mathrm{Ca}^{2+}$ influx is most likely involved in the increase of $\left[\mathrm{Ca}^{2+}\right]_{\mathrm{i}}$ by CaSR agonists. To evaluate whether TRPC6 contributes to $\left[\mathrm{Ca}^{2+}\right]_{\mathrm{i}}$ increase induced by CaSR activation, we transfected human podocytes with specific siRNA to downregulate 


\section{A}

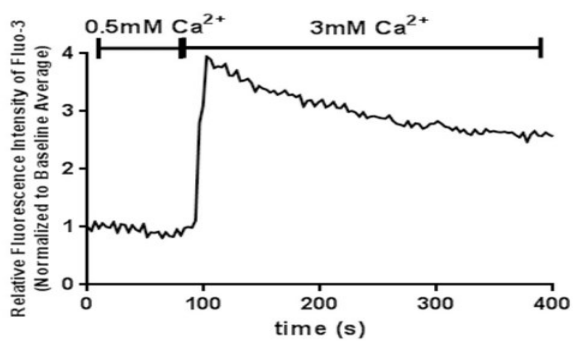

C

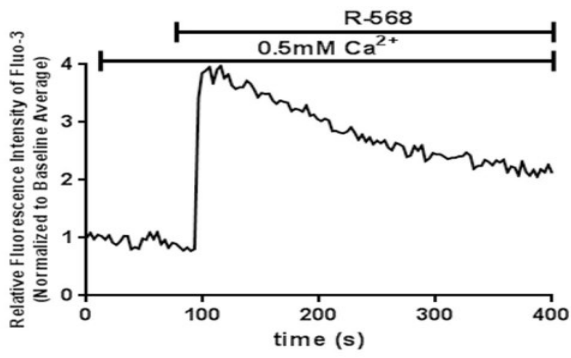

E

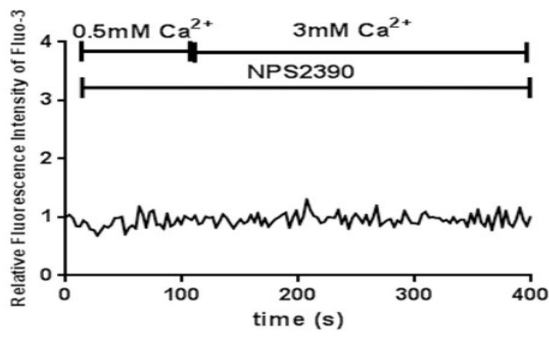

$\mathbf{G}$

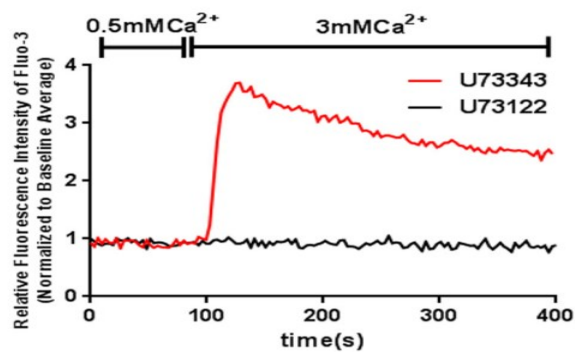

B

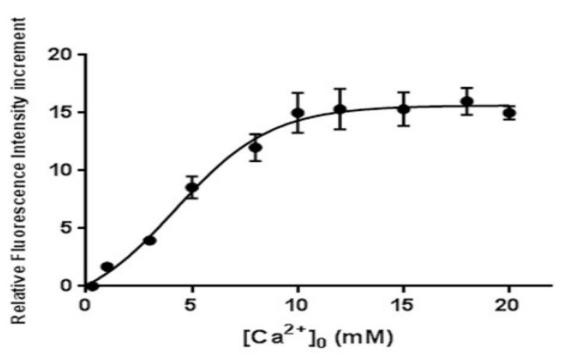

D

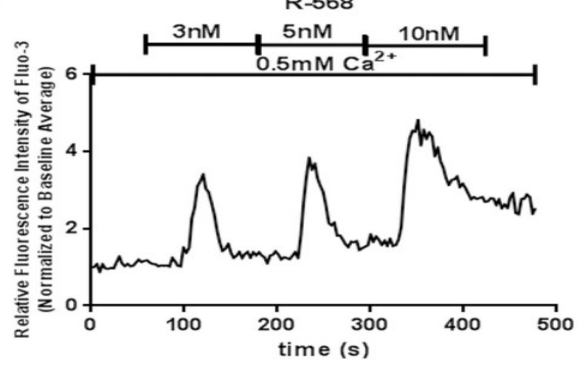

$\mathbf{F}$

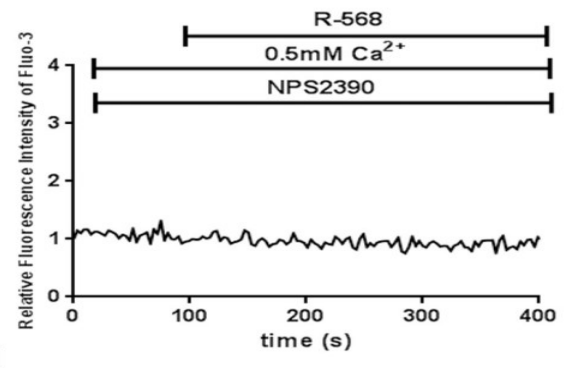

H

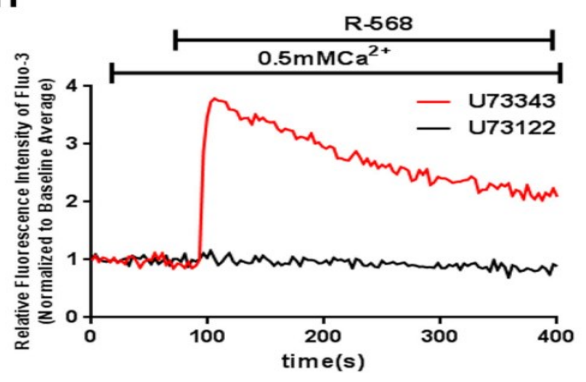

Fig. 2. CaSR activation by $\mathrm{Ca}^{2+}$ and $\mathrm{R}-568$ results in a $\left[\mathrm{Ca}^{2+}\right]_{\mathrm{i}}$ increase. Confocal microscopy using Fura-3 fluorescent dye was used to observe changes in the $\mathrm{Ca}^{2+}$ concentration. (A) Change in $\left[\mathrm{Ca}^{2+}\right]_{0}$ from $0.5 \mathrm{mmol} / \mathrm{L}$ to $3 \mathrm{mmol} / \mathrm{L}$ induced a rapid increase to a peak level, which was maintained for more than 300 seconds after the peak. (B) Extracellular $\mathrm{Ca}^{2+}(0.5-20 \mathrm{mmol} / \mathrm{L})$ induced a $\left[\mathrm{Ca}^{2+}\right]_{\mathrm{i}}$ increase in podocytes in a dose-dependent manner; data are shown as the mean \pm SE of 20-30 cells. (C) In the presence of extracellular $\mathrm{Ca}^{2+}$ at 0.5 $\mathrm{mmol} / \mathrm{L}$, the addition of $10 \mathrm{nmol} / \mathrm{L} \mathrm{R}-568$ induced a rapid increase in $\left[\mathrm{Ca}^{2+}\right]_{\mathrm{i}}$ to a peak level and a slower decrease. (D) In the presence of extracellular $\mathrm{Ca}^{2+}$ at $0.5 \mathrm{mmol} / \mathrm{L}$, the addition of various doses of R-568 (3, 5, $10 \mathrm{nmol} / \mathrm{L}$ ) induced $\left[\mathrm{Ca}^{2+}\right]_{\mathrm{i}}$ increases in a dose-dependent manner. (E, F) $10 \mu \mathrm{mol} / \mathrm{L}$ of the CaSR antagonist NPS2390 significantly inhibited $\left[\mathrm{Ca}^{2+}\right]_{\mathrm{i}}$ increase induced by $3 \mathrm{mmol} / \mathrm{L}\left[\mathrm{Ca}^{2+}\right]_{0}$ or $10 \mathrm{nmol} / \mathrm{L} \mathrm{R}-568(\mathrm{p}<0.01$ vs. NPS2390 (-), n = 3). (G, H) $30 \mu \mathrm{mol} / \mathrm{L}$ of the PLC inhibitor U73122 inhibited $\left[\mathrm{Ca}^{2+}\right]_{\mathrm{i}}$ increase induced by $3 \mathrm{mmol} / \mathrm{L}\left[\mathrm{Ca}^{2+}\right]_{0}$ or $10 \mathrm{nmol} / \mathrm{L} \mathrm{R}-568$ compared with U73343, an inactive analog of U73122. (p<0.01 vs. U73343, $n=3$ ) Number of trials = 3; 20-30 cells were selected in each trial.

the expression of TRPC6. The efficiency of TRPC6-siRNA was confirmed by western blot analyses (Fig. 3C). Compared with cells transfected with scrambled siRNA, transfection with TRPC6 siRNA partially, but significantly, inhibited the R-568-induced $\left[\mathrm{Ca}^{2+}\right]_{\mathrm{i}}$ increase by $37.94 \%$ ( $<<0.001, \mathrm{n}=3$; Fig. 3D). TRPC6 knockdown also attenuated the $\left[\mathrm{Ca}^{2+}\right]_{0}$-induced KARGER 


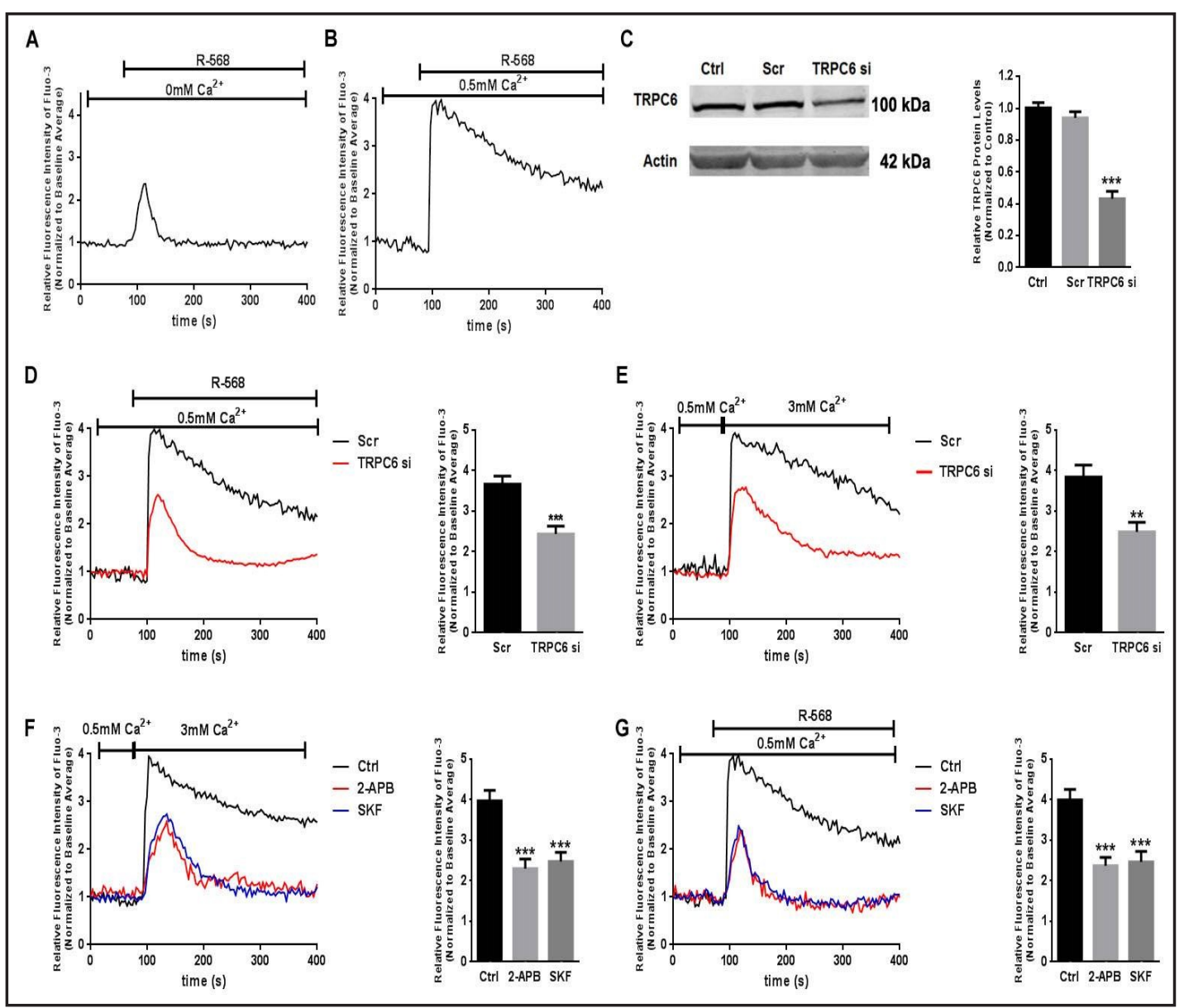

Fig. 3. TRPC6 participates in CaSR activation-induced $\left[\mathrm{Ca}^{2+}\right]_{\mathrm{i}}$ increase. Confocal microscopy using Fura-3 fluorescent dye was used to observe changes in the $\mathrm{Ca}^{2+}$ concentration. (A) In extracellular fluid lacking calcium, the addition of R-568 to a final concentration of $10 \mathrm{nmol} / \mathrm{L}$ induced a transient increase in [Ca ${ }^{2+}$ ] $\mathrm{i}^{*}$ (B) In the presence of extracellular $\mathrm{Ca}^{2+}$ at $0.5 \mathrm{mmol} / \mathrm{L}$, the addition of $10 \mathrm{nmol} / \mathrm{L} \mathrm{R}-568$ induced a rapid increase in $\left[\mathrm{Ca}^{2+}\right]_{\mathrm{i}}$ to a peak level and a slower decrease. (C) Western blot experiments showed that transfection with TRPC6 siRNA reduced TRPC6 protein expression $\left({ }^{* * *} \mathrm{p}<0.001\right.$ vs. Scr, $\mathrm{n}=3$ ). (D) TRPC6 siRNA transfection inhibited calcium signal induced by $10 \mathrm{nmol} / \mathrm{L} \mathrm{R}-568$ ( ${ }^{* *} \mathrm{p}<0.001 \mathrm{vs}$. Scr, $\mathrm{n}=3$ ). (E) TRPC6 siRNA transfection inhibited calcium signal induced by $3 \mathrm{mmol} / \mathrm{L}\left[\mathrm{Ca}^{2+}\right]_{0^{*}}{ }^{* *} \mathrm{p}<0.01 \mathrm{vs}$. Scr). (F) The $3 \mathrm{mM}$ $\left[\mathrm{Ca}^{2+}\right]_{0}$-induced $\left[\mathrm{Ca}^{2+}\right]_{\mathrm{i}}$ increase is inhibited in the presence of TRPC channel blockers $(* * * \mathrm{p}<0.001 \mathrm{vs}$. Ctrl, $\mathrm{n}=3$ ). Cells were pretreated with $50 \mu \mathrm{M}$ SKF-96365 or $100 \mu \mathrm{M}$ 2-APB for $20 \mathrm{~min}$ in a medium containing $0.5 \mathrm{mM} \mathrm{Ca}^{2+}$ followed by a change to $3 \mathrm{mM}$. (G) The $10 \mathrm{nmol} / \mathrm{L} \mathrm{R}-568$ induced $\left[\mathrm{Ca}^{2+}\right]_{\mathrm{i}}$ increase is inhibited in the presence of TRPC channel blockers ( ${ }^{* * *} \mathrm{p}<0.001$ vs. Ctrl, $\mathrm{n}=3$ ). Cells were pretreated with $50 \mu \mathrm{M}$ SKF96365 or $100 \mu \mathrm{M} 2$-APB for $20 \mathrm{~min}$ in medium containing $0.5 \mathrm{mM} \mathrm{Ca}^{2+}$ followed by the addition of $10 \mathrm{nmol} / \mathrm{L}$ R-568. Number of trials $=3 ; 20-30$ cells were selected in each trial. + SKF96365: podocytes pretreated with SKF96365 for $20 \mathrm{~min}$. +2-APB: podocytes pretreated with 2-APB for $20 \mathrm{~min}$.

$\left[\mathrm{Ca}^{2+}\right]_{\mathrm{i}}$ increase (Fig. 3E). Transfection with scrambled siRNA did not alter $\left[\mathrm{Ca}^{2+}\right]_{0}-$ or the R-568-induced $\left[\mathrm{Ca}^{2+}\right]_{\mathrm{i}}$ increase compared with the non-transfected control (data not shown). In addition, the pharmacological blockage of TRPC6 with SKF96365 (50 $\mu \mathrm{M})$ or 2-APB $(100$ $\mu \mathrm{M})$, nonselective TRPC channel blockers, significantly inhibited $\left[\mathrm{Ca}^{2+}\right]_{0}-$ and the R-568induced $\left[\mathrm{Ca}^{2+}\right]_{\mathrm{i}}$ increase, respectively (Fig. 3F and 3G). Taken together, these data indicated that TRPC6 is involved in the increase of $\left[\mathrm{Ca}^{2+}\right]_{i}$ by CaSR activation. 


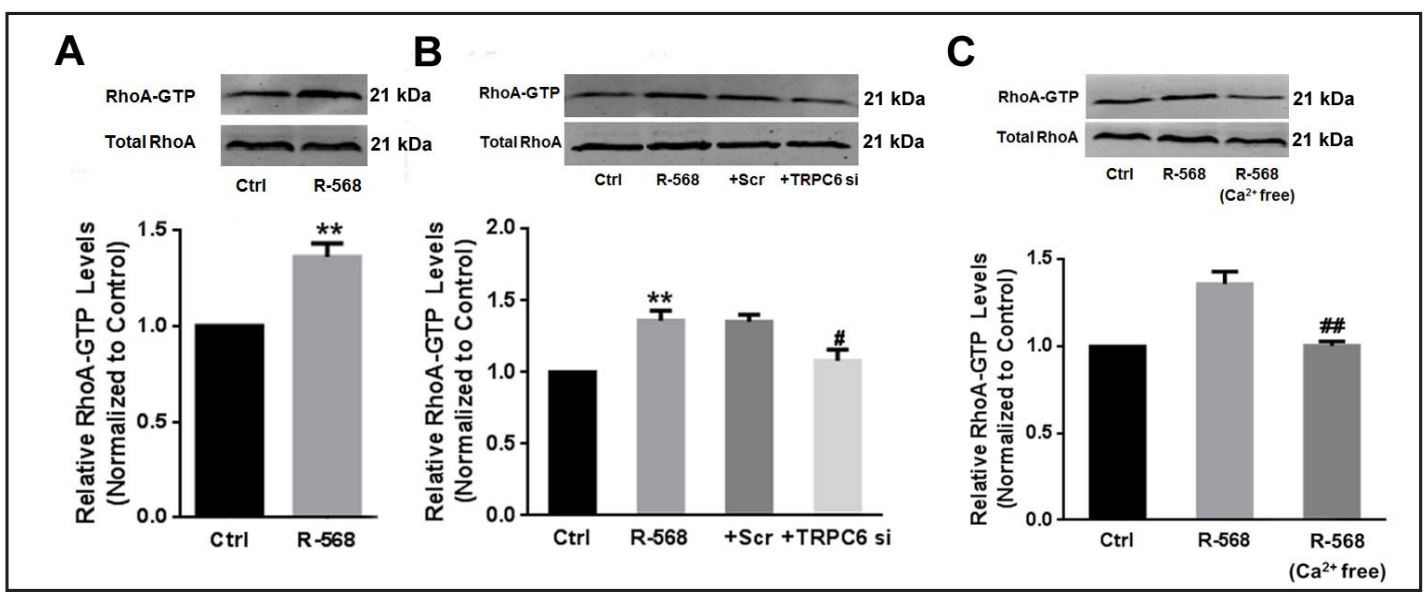

Fig. 4. CaSR activation induces an increase in expression of active RhoA and it is dependent on TRPC6dependent $\mathrm{Ca}^{2+}$ influx. (A) R-568 treatment induced a significant increase in active RhoA expression in podocytes. ( ${ }^{* *} \mathrm{p}<0.01$ vs. R-568, $\mathrm{n}=3$ ). (B) TRPC6 siRNA transfection reversed the increase in active RhoA induced by R-568 treatment. ( ${ }^{* *} \mathrm{p}<0.01$ vs. Ctrl, ${ }^{*} \mathrm{p}<0.05$ vs. R-568, ${ }^{*} \mathrm{p}<0.05$ vs. R-568 + Scr, $\mathrm{n}=3$ ). +Scr: R-568+Scr, +TRPC6: R-568+TRPC6. (C) In the absence of extracellular $\mathrm{Ca}^{2+}$ (in the present of 1 mM EGTA), the R-568-induced increase in RhoA activity was significantly reduced ( $p<0.05$ vs. Ctrl, $n=3$ ).

TRPC6-dependent $\mathrm{Ca}^{2+}$ influx are required for RhoA activation induced by CaSR stimulation

RhoA activity was directly assessed by an affinity pull-down assay using the GST fusion protein rhotekin, which recognizes only the active form of RhoA (GTP-RhoA). As shown in Fig. $4 \mathrm{~A}$, treatment of podocytes with $10 \mathrm{nmol} / \mathrm{L} \mathrm{R}-568$ for $30 \mathrm{~min}$ caused a significant increase in RhoA activity compared with the control $(\mathrm{p}<0.01 ; \mathrm{n}=3)$. The effect may be attributed to R-568-induced TRPC6 activation because transfection with TRPC6 siRNA attenuated the R-568-induced increase in RhoA activity (Fig. 4B), compared with cells transfected with scrambled siRNA $(\mathrm{p}<0.001 ; \mathrm{n}=3)$. The transfection of scrambled siRNA did not affect RhoA activity. To further assess the contribution of $\mathrm{Ca}^{2+}$ influx in the increase in RhoA activity induced by CaSR activation, extracellular $\mathrm{Ca}^{2+}$ was depleted with $1 \mathrm{mM}$ EGTA. As shown in Fig. 4C, the R-568-induced increase in RhoA activity was significantly reduced in the absence of extracellular $\mathrm{Ca}^{2+}(p<0.01 ; \mathrm{n}=3)$. These findings indicated that upon activation of CaSR, the TRPC6-dependent $\mathrm{Ca}^{2+}$ influx contributes to RhoA activation.

TRPC6 regulates stress fiber formation and focal adhesions via RhoA in response to CaSR stimulation

To evaluate the functional role of TRPC6 on the CaSR activation-induced actin cytoskeleton, podocytes were stained with FITC-phalloidin. Because focal adhesions are required for the formation of stress fibers, focal adhesions were assessed by anti-vinculin immunostaining. In line with previous findings, treatment of podocytes with $10 \mathrm{nmol} / \mathrm{L} \mathrm{R}$ 568 for 30 min significantly increased the numbers of stress fibers by approximately $32 \%$ compared with controls (Fig. 5A). A targeted siRNA approach to knockdown of RhoA was used to evaluate the effects of RhoA activity on changes in the actin cytoskeleton induced by R-568. The efficiency of RhoA-siRNA was confirmed by western blot analyses (Fig. 5B). As shown in Fig. 5C, transfection with RhoA-siRNA significantly abolished the increase in stress fibers and focal adhesions induced by R-568 compared with transfection with scrambled siRNA ( $\mathrm{p}<0.001, \mathrm{n}=3$ ). As expected, transfection with TRPC6-siRNA also attenuated the increase in stress fibers and focal adhesions induced by R-568 (Fig. 5D, $p<0.001, n=3$ ). These findings suggested that TRPC6-mediated RhoA activation is associated with the changes in the actin cytoskeleton induced by CaSR stimulation.

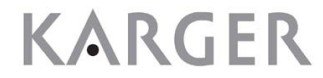


Fig. 5. The role of TRPC6 and RhoA in the formation of stress fibers and focal adhesions induced by CaSR activation. Podocytes were doublelabel stained with FITC-phalloidin for stress fibers (green) and with vinculin antibodies (red). (A) R-568 treatment enhanced the formation of stress fibers and focal adhesions. Left, representative image; right, quantification evaluation. $\quad * * \mathrm{p}<0.01$ vs. Ctrl. (B) Western blot experiments showed that transfection with RhoA siRNA reduced RhoA protein expression $\left({ }^{* * *} \mathrm{p}<0.001\right.$ vs. Scr, $\mathrm{n}=3$ ). (C) RhoA siRNA transfection reversed the forma-
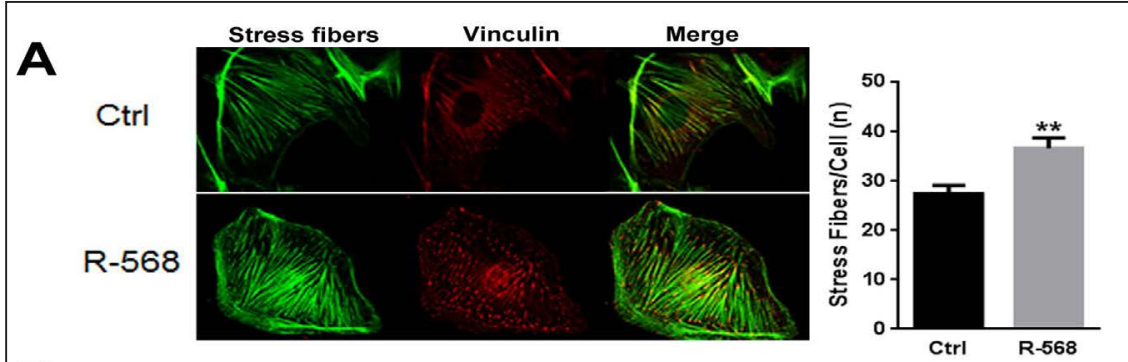

B
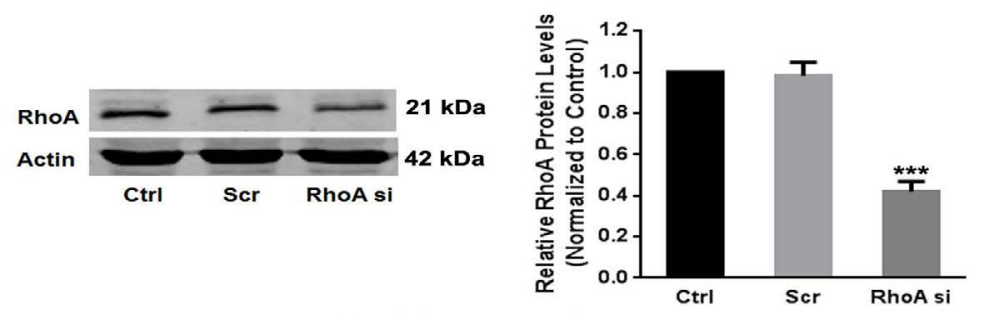

C

R-568

$+\mathrm{Scr}$
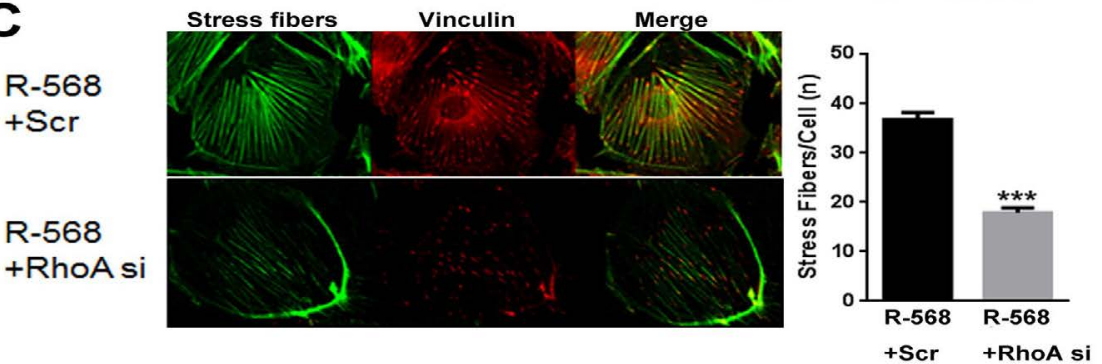

D
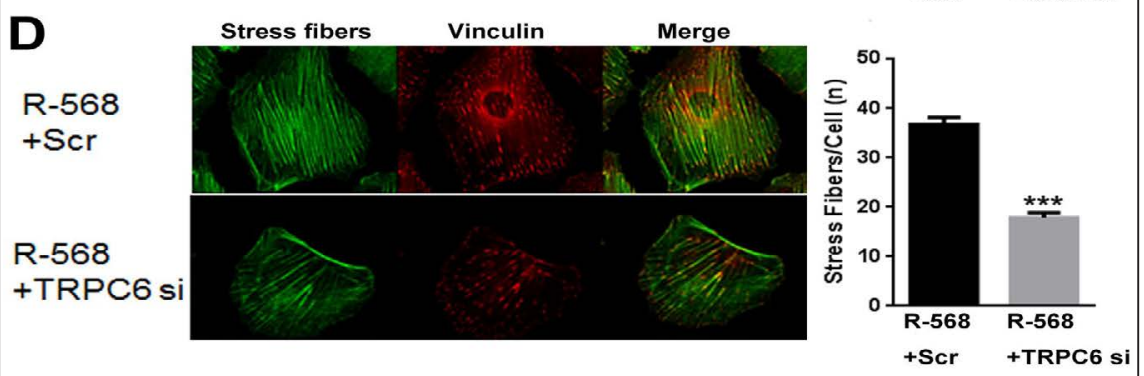

tion of stress fibers

and focal adhesions induced by R-568 treatment. Left, representative image; right, quantification evaluation. ${ }^{* *}$ p $<0.001$ vs. R-568+Scr. (D) TRPC6 knockdown also abolished the changes in actin cytoskeleton by R-568 treatment. Left, representative image; right, quantification evaluation. ${ }^{* * *} \mathrm{p}<0.001$ vs. R-568+Scr. Number of trials $=3$; more than 50 cells were selected in each trial.

\section{Discussion}

Podocytes are highly differentiated epithelial cells that form the final barrier to protein loss. The podocyte foot processes form specialized cell junctions known as slit diaphragms, which are dynamically modified by actin cytoskeleton. Podocyte dysfunction and actin cytoskeleton disorganization lead to foot process effacement, disruption of slit diaphragms and proteinuria [19, 23-26]. Recently, several interesting studies have revealed that CaSR agonists, which are widely used to treat secondary hyperparathyroidism in patients with end-stage renal failure, have direct renoprotective actions $[8,9]$. The direct protective effects of CaSR agonists may be mediated through actions on the actin cytoskeleton because R-568 increases actin stress fiber formation and focal adhesions and improves actin disorganization induced by puromycin aminonucleoside [9]. An investigation of the underlying mechanisms will provide a new treatment strategy for chronic kidney disease. In the present study, we 
demonstrate that CaSR activation induces TRPC6-dependent $\mathrm{Ca}^{2+}$ influx, which mediates actin stress fiber formation induced by CaSR agonist via the RhoA pathway. This mechanism may explain the direct protective action of CaSR agonists.

Although downstream effects can be highly varied, the first reactions following CaSR activation are common; the stimulation of CaSR evokes an increase in $\left[\mathrm{Ca}^{2+}\right]_{i}[1,10]$. However, the source of the $\left[\mathrm{Ca}^{2+}\right]_{i}$ increase is cellular context-dependent. In this study, we show that CaSR stimulation in human podocytes induces not only $\mathrm{Ca}^{2+}$ release from the $\mathrm{Ca}^{2+}$ stores but also TRPC6-dependent $\mathrm{Ca}^{2+}$ entry. As shown in Fig. 2, both high $\left[\mathrm{Ca}^{2+}\right]_{0}$ and R-568 induced an increase in $\left[\mathrm{Ca}^{2+}\right]_{\mathrm{i}}$ that included an initial rapid increase, which may represent intracellular $\mathrm{Ca}^{2+}$ mobilization, followed by a sustained increase, which may represent $\mathrm{Ca}^{2+}$ entry. Indeed, our experiments indicate that TRPC6 is at least partly responsible for the $\mathrm{Ca}^{2+}$ entry induced by CaSR stimulation because it is significantly abolished by both the pharmacological blockage of TRPC6 and the knockdown of TRPC6. CaSR is a group C GPCR that interacts with PLC through $\mathrm{G}_{\mathrm{g} 11}$ subunits of heterotrimeric G proteins, and therefore, its activation produces IP ${ }_{3}$ and DAG. It is now widely accepted that TRPC6 can function as DAGactivated channels associated with the N-terminus (3-56 amino acids) of the TRPC6 protein $[27,28]$. Therefore, it is likely that TRPC 6 can be activated by the PLC-dependent production of DAG in response to CaSR stimulation. Our study also observed that the PLC inhibitor almost completely abolished the R-568-induced $\left[\mathrm{Ca}^{2+}\right]_{\mathrm{i}}$ increase. Compelling evidence has revealed that in colonic epithelial cells, CaSR stimulation by $5 \mathrm{mM}\left[\mathrm{Ca}^{2+}\right]_{0}$ triggers DAG production [29], and in vascular smooth muscle cells, the upregulated TRPC6 mediated by CaSR is functionally sensitive to DAG [12]. DAG can directly increase TRPC6 activity and does not seem to affect the plasma membrane expression of TRPC6 [27, 28]. It is unclear whether CaSR stimulation in podocytes increases the plasma membrane expression of TRPC6 through another mechanism, and this topic warrants further investigation. Although group C GPCRs are molecularly distinct, their pharmacological profiles overlap, and they are constitutive dimers (either homo or hetero) [30]. The heterodimerization of CaSR with group I metabotropic glutamate receptors (mRluR1) in neurons has been established [31]. Interestingly, mRluR1 is also expressed in podocytes and may regulate actin cytoskeleton organization $[32,33]$. Our unpublished data suggest that TRPC6 is involved in intracellular calcium signals induced by mRluR activation. Whether there is heterodimerization of CaSR with mRluR1 in podocyte and what its functional role is will be is a valuable topic to investigate. Although voltage-gated calcium channels are not expressed in podocytes, [23] and TRPC6 is predominant among the $\mathrm{Ca}^{2+}$ permeable channels [16], other TRPC channels, such as TRPC5, and the ionotropic N-methyl-D-aspartate (NMDA) receptor also occur [34]. Therefore, this study cannot rule out the involvement of other calcium channels in the CaSR activation-induced $\mathrm{Ca}^{2+}$ influx.

Consistent with a previous study [9], our results demonstrate that CaSR stimulation with R-568 produces an increase in RhoA activity in podocytes. Interestingly, our study showed that the increased RhoA activity can be inhibited by transfection of TRPC6 siRNA, suggesting TRPC6-dependent $\mathrm{Ca}^{2+}$ entry is required for the activation of RhoA upon CaSR stimulation. CaSR stimulation inducing the activation of RhoA has been reported in several cell types, such as HEK-293 cells [35], Madin-Darby canine kidney (MDCK) cells [36], esophageal epithelial cells [37], renal collecting duct cells [38] and colonic epithelial cells [29]. However, the underlying mechanisms are unclear and may be highly dependent on cell type. In MDCK cells, CaSR stimulation induces RhoA activation via a $G_{12 / 13}$ signal pathway [36], whereas in HEK-293 cells, this occurs via a $G_{q / 11}$ signal pathway [35]. In HEK-293 cells, the activation of $\mathrm{G}_{\mathrm{q}}$ coupled to CaSR induces the interaction between the $\mathrm{C}$ terminal of CaSR and rho-guanine nucleotide exchange factors, which mediate RhoA activity [35]. Thus, there is a strong possibility that the activated $G_{q}$ protein contributes to TRPC6 activation via the PLC pathway. Indeed, other GPCRs mediating RhoA activity via the $G_{q}$ signaling pathway have widely been reported; however, relatively little is known about the involvement of TRPC6 in the activation of RhoA. Upon thrombin stimulation, TRPC6-dependent $\mathrm{Ca}^{2+}$ entry, but with neither other store-operated $\mathrm{Ca}^{2+}$ entry nor the release of calcium stores, is required 


\section{Cellular Physiology Cell Physiol Biochem 2017;43:1777-1789 \begin{tabular}{l|l|l} 
DOI: 10.1159/000484064 & $\begin{array}{l}\text { O 2017 The Author(s). Published by S. Karger AG, Basel } \\
\text { www.karger.com/cpb }\end{array}$
\end{tabular}

for RhoA activation and the consequent stress fiber formation in endothelial cells [39]. In podocytes, TRPC6 is also responsible for RhoA activation and stress fiber formation induced by angiotensin II stimulation [16].

It has been well accepted that RhoA promotes the formation of stress fibers and focal adhesion, producing a stationary podocyte phenotype, interpreted as a stable foot process, whereas the activity of Cdc42/Rac1 underlies the motile phenotype [19]. In line with this concept and a previous study, our study reveals that the inhibition of RhoA activity abolishes the formation of stress fibers and focal adhesions mediated by CaSR activation. Given the role of TRPC6 on the activation of RhoA mediated by CaSR stimulation in podocytes, it is not surprising that the blockage of TRPC6 abolishes the formation of stress fibers mediated by CaSR stimulation. This may indicate that TRPC6 is involved in the regulation of the actin cytoskeleton via the RhoA signaling pathway in response to CaSR stimulation. It remains unclear how the TRPC6 signal and the CaSR signal of podocytes are integrated for the CaSR stimulation. It has been demonstrated that, in podocytes, TRPC6 is localized in the lipid raft domain at plasma membranes [40] and TRPC6 is in a molecular complex with RhoA [16]. In some cell types, CaSR is distributed in a caveolin-rich plasma membrane domain [1]; however, this distribution does not seem to occur in podocytes [9]. This distribution requires further investigation.

\section{Acknowledgements}

This work was supported by the National Nature Science Foundation of China (81441023).

\section{Disclosure Statement}

The authors declare that no Disclosure Statement exists.

\section{References}

1 Hofer AM, Brown EM: Extracellular calcium sensing and signalling. Nat Rev Mol Cell Biol 2003;4:530-538.

12 Ward DT: Calcium receptor-mediated intracellular signalling. Cell Calcium 2004;35:217-228.

3 Ogata H, Ritz E, Odoni G, Amann K, Orth SR: Beneficial effects of calcimimetics on progression of renal failure and cardiovascular risk factors. J Am Soc Nephrol 2003;14:959-967.

4 Riccardi D, Valenti G: Localization and function of the renal calcium-sensing receptor. Nat Rev Nephrol 2016;12:414-425.

-5 Graca JA, Schepelmann M, Brennan SC, Reens J, Chang W, Yan P, Toka H, Riccardi D, Price SA: Comparative expression of the extracellular calcium-sensing receptor in the mouse, rat, and human kidney. Am J Physiol Renal Physiol 2016;310:F518-533.

6 Meng K, Xu J, Zhang C, Zhang R, Yang H, Liao C, Jiao J: Calcium sensing receptor modulates extracellular calcium entry and proliferation via TRPC3/6 channels in cultured human mesangial cells. PLoS One 2014;9:e98777.

-7 Kwak JO, Kwak J, Kim HW, Oh KJ, Kim YT, Jung SM, Cha SH: The extracellular calcium sensing receptor is expressed in mouse mesangial cells and modulates cell proliferation. Exp Mol Med 2005;37:457-465.

-8 Gut N, Piecha G, Pradel A, Geldyyev A, Potemkina A, Ritz E, Regele H, Schmitt CP, Gross-Weissmann ML: The calcimimetic R-568 prevents podocyte loss in uninephrectomized ApoE-/- mice. Am J Physiol Renal Physiol 2013;305:F277-285.

9 Oh J, Beckmann J, Bloch J, Hettgen V, Mueller J, Li L, Hoemme M, Gross ML, Penzel R, Mundel P, Schaefer F, Schmitt CP: Stimulation of the calcium-sensing receptor stabilizes the podocyte cytoskeleton, improves cell survival, and reduces toxin-induced glomerulosclerosis. Kidney Int 2011;80:483-492.

$>10$ Rastaldi MP: Calcium sensing in podocytes. Kidney Int 2011;80:445-447. 


\section{Cellular Physiology Cell Physiol Biochem 2017;43:1777-1789

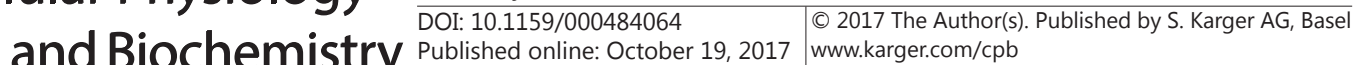

11 Bandyopadhyay BC, Swaim WD, Sarkar A, Liu X, Ambudkar IS: Extracellular Ca(2+) sensing in salivary ductal cells. J Biol Chem 2012;287:30305-30316.

-12 Tang H, Yamamura A, Yamamura H, Song S, Fraidenburg DR, Chen J, Gu Y, Pohl NM, Zhou T, Jimenez-Perez L, Ayon RJ, Desai AA, Goltzman D, Rischard F, Khalpey Z, Black SM, Garcia JG, Makino A, Yuan JX: Pathogenic role of calcium-sensing receptors in the development and progression of pulmonary hypertension. Am J Physiol Lung Cell Mol Physiol 2016;310:L846-859.

-13 Chow JY, Estrema C, Orneles T, Dong X, Barrett KE, Dong H: Calcium-sensing receptor modulates extracellular $\mathrm{Ca}(2+)$ entry via TRPC-encoded receptor-operated channels in human aortic smooth muscle cells. Am J Physiol Cell Physiol 2011;301:C461-468.

14 Cai S, Fatherazi S, Presland RB, Belton CM, Roberts FA, Goodwin PC, Schubert MM, Izutsu KT: Evidence that TRPC1 contributes to calcium-induced differentiation of human keratinocytes. Pflugers Arch 2006;452:4352.

15 El Hiani Y, Ahidouch A, Lehen'kyi V, Hague F, Gouilleux F, Mentaverri R, Kamel S, Lassoued K, Brule G, Ouadid-Ahidouch H: Extracellular signal-regulated kinases 1 and 2 and TRPC1 channels are required for calcium-sensing receptor-stimulated MCF-7 breast cancer cell proliferation. Cell Physiol Biochem 2009;23:335-346.

16 Tian D, Jacobo SM, Billing D, Rozkalne A, Gage SD, Anagnostou T, Pavenstadt H, Hsu HH, Schlondorff J, Ramos A, Greka A: Antagonistic regulation of actin dynamics and cell motility by TRPC5 and TRPC6 channels. Sci Signal 2010;3:ra77.

17 Goel M, Sinkins WG, Zuo CD, Estacion M, Schilling WP: Identification and localization of TRPC channels in the rat kidney. Am J Physiol Renal Physiol 2006;290:F1241-1252.

-18 Greka A, Mundel P: Balancing calcium signals through TRPC5 and TRPC6 in podocytes. J Am Soc Nephrol 2011;22:1969-1980.

19 Wieder N, Greka A: Calcium, TRPC channels, and regulation of the actin cytoskeleton in podocytes: towards a future of targeted therapies. Pediatr Nephrol 2016;31:1047-1054.

-20 Zhang HT, Wang WW, Ren LH, Zhao XX, Wang ZH, Zhuang DL, Bai YN: The mTORC2/Akt/NFkappaB pathwaymediated activation of TRPC6 participates in adriamycin-induced podocyte apoptosis. Cell Physiol Biochem 2016;40:1079-1093.

21 Yang H, Zhao B, Liao C, Zhang R, Meng K, Xu J, Jiao J: High glucose-induced apoptosis in cultured podocytes involves TRPC6-dependent calcium entry via the RhoA/ROCK pathway. Biochem Biophys Res Commun 2013;434:394-400.

22 Saleem MA, O’Hare MJ, Reiser J, Coward RJ, Inward CD, Farren T, Xing CY, Ni L, Mathieson PW, Mundel P: A conditionally immortalized human podocyte cell line demonstrating nephrin and podocin expression. J Am Soc Nephrol 2002;13:630-638.

-23 Dryer SE, Reiser J: TRPC6 channels and their binding partners in podocytes: role in glomerular filtration and pathophysiology. Am J Physiol Renal Physiol 2010;299:F689-701.

24 Wang B, Xu X, He X, Wang Z, Yang M: Berberine improved Aldo-induced podocyte injury via inhibiting oxidative stress and endoplasmic reticulum stress pathways both In vivo and In vitro. Cell Physiol Biochem 2016;39:217-228.

-25 Liu Y, Su L, Lin Q, Han Y, You P, Fan Q: Induction of C-Mip by IL-17 plays an important role in adriamycininduced podocyte damage. Cell Physiol Biochem 2015;36:1274-1290.

-26 Chen T, Zheng LY, Xiao W, Gui D, Wang X, Wang N: Emodin ameliorates high glucose induced-podocyte epithelial-mesenchymal transition in-vitro and in-vivo. Cell Physiol Biochem 2015;35:1425-1436.

27 Bouron A, Chauvet S, Dryer S, Rosado JA: Second Messenger-Operated Calcium Entry Through TRPC6. Adv Exp Med Biol 2016;898:201-249.

28 Zhang L, Saffen D: Muscarinic acetylcholine receptor regulation of TRP6 Ca2+ channel isoforms. Molecular structures and functional characterization. J Biol Chem 2001;276:13331-13339.

-29 Rey O, Young SH, Jacamo R, Moyer MP, Rozengurt E: Extracellular calcium sensing receptor stimulation in human colonic epithelial cells induces intracellular calcium oscillations and proliferation inhibition. J Cell Physiol 2010;225:73-83.

-30 Riccardi D, Kemp PJ: The calcium-sensing receptor beyond extracellular calcium homeostasis: conception, development, adult physiology, and disease. Annu Rev Physiol 2012;74:271-297.

-31 Gama L, Wilt SG, Breitwieser GE: Heterodimerization of calcium sensing receptors with metabotropic glutamate receptors in neurons. J Biol Chem 2001;276:39053-39059. 


\section{Cellular Physiology Cell Physiol Biochem 2017;43:1777-1789 \begin{tabular}{l|l|l} 
DOI: 10.1159/000484064 & $\begin{array}{l}\text { O 2017 The Author(s). Published by S. Karger AG, Basel } \\
\text { www.karger.com/cpb }\end{array}$ \\
\hline
\end{tabular}

32 Puliti A, Rossi PI, Caridi G, Corbelli A, Ikehata M, Armelloni S, Li M, Zennaro C, Conti V, Vaccari CM, Cassanello M, Calevo MG, Emionite L, Ravazzolo R, Rastaldi MP: Albuminuria and glomerular damage in mice lacking the metabotropic glutamate receptor 1. Am J Pathol 2011;178:1257-1269.

33 Gu L, Liang X, Wang L, Yan Y, Ni Z, Dai H, Gao J, Mou S, Wang Q, Chen X, Wang L, Qian J: Functional metabotropic glutamate receptors 1 and 5 are expressed in murine podocytes. Kidney Int 2012;81:458468.

34 Giardino L, Armelloni S, Corbelli A, Mattinzoli D, Zennaro C, Guerrot D, Tourrel F, Ikehata M, Li M, Berra S, Carraro M, Messa P, Rastaldi MP: Podocyte glutamatergic signaling contributes to the function of the glomerular filtration barrier. J Am Soc Nephrol 2009;20:1929-1940.

35 Pi M, Spurney RF, Tu Q, Hinson T, Quarles LD: Calcium-sensing receptor activation of rho involves filamin and rho-guanine nucleotide exchange factor. Endocrinology 2002;143:3830-3838.

36 Huang C, Hujer KM, Wu Z, Miller RT: The Ca2+-sensing receptor couples to Galpha12/13 to activate phospholipase D in Madin-Darby canine kidney cells. Am J Physiol Cell Physiol 2004;286:C22-30.

37 Abdulnour-Nakhoul S, Brown KL, Rabon EC, Al-Tawil Y, Islam MT, Schmieg JJ, Nakhoul NL: Cytoskeletal changes induced by allosteric modulators of calcium-sensing receptor in esophageal epithelial cells. Physiol Rep 2015;3: e12616.

-38 Valenti G, Mira A, Mastrofrancesco L, Lasorsa DR, Ranieri M, Svelto M: Differential modulation of intracellular $\mathrm{Ca} 2+$ responses associated with calcium-sensing receptor activation in renal collecting duct cells. Cell Physiol Biochem 2010;26:901-912.

-39 Singh I, Knezevic N, Ahmmed GU, Kini V, Malik AB, Mehta D: Galphaq-TRPC6-mediated Ca2+ entry induces RhoA activation and resultant endothelial cell shape change in response to thrombin. J Biol Chem 2007;282:7833-7843.

-40 Kim EY, Anderson M, Wilson C, Hagmann H, Benzing T, Dryer SE: NOX2 interacts with podocyte TRPC6 channels and contributes to their activation by diacylglycerol: essential role of podocin in formation of this complex. Am J Physiol Cell Physiol 2013;305:C960-971. 